\title{
Methacholine challenge in preschool children: methacholine- induced wheeze versus transcutaneous oximetry
}

\author{
S.C. Yong, C.M. Smith, R. Wach, M. Kurian, R.A. Primhak
}

\begin{abstract}
Methacholine challenge in preschool children: methacholine-induced wheeze versus transcutaneous oximetry. S.C. Yong, C.M. Smith, R. Wach, M. Kurian, R.A. Primhak. (C) ERS Journals Ltd 1999.
\end{abstract}

ABSTRACT: Tracheal/chest auscultation for wheeze and transcutaneous oximetry have both been suggested as measures of outcome in bronchial provocation tests in young children. This study aimed to compare the sensitivity and safety of these two techniques as end-points for methacholine challenge in children aged $<4$ yrs.

Seventy-two methacholine challenges were performed in 39 children aged $<4$ yrs with recurrent wheeze. Arterial oxygen saturation $\left(\mathrm{S}_{\mathrm{a}}, \mathrm{O}_{2}\right)$ and transcutaneous oxygen pressure tc $\mathrm{PO}_{2}$ continuously, and the test was terminated when wheeze was heard or at $\mathrm{S}_{\mathrm{a}}, \mathrm{O}_{2}<91 \%$. tc $\mathrm{PO}_{2}$ was not used as an end-point.

Wheeze or desaturation occurred at $\leq 8 \mathrm{mg} \cdot \mathrm{mL}^{-1}$ methacholine in every test. One child had transient clinical cyanosis, but no other ill-effects were seen. Fifty-six tests (78\%) were terminated for wheeze, seven $(10 \%)$ for fall in $S_{\mathrm{a}}, \mathrm{O}_{2}$ and nine $(\mathbf{1 2 \%})$ showed simultaneous responses in both parameters. Twenty-eight tests (39\%) contained a fall in $\mathrm{tcPO}_{2}>3 \mathrm{kPa}$ but six of these also showed a significant rise. Fifty-three tests $(75 \%)$ contained a fall in $\mathrm{tcPO}_{2}>15 \%$, but 20 of these also showed a significant rise.

Tracheal/chest auscultation with $S_{\mathrm{a}, \mathrm{O}_{2}}$ monitoring is a sensitive and relatively safe end-point for bronchial challenges in preschool children. The erratic pattern of transcutaneous oxygen pressure response in some children casts doubt on its reliability as a proxy measure of bronchial obstruction.

Eur Respir J 1999; 14: 1175-1178.

The measurement of bronchial responsiveness in preschool children is a potentially useful clinical and research tool, but it is hampered by the fact that lung function measurement in preschool children is technically difficult without sedation. Several indirect methods have been used to assess bronchial responsiveness to methacholine challenge in this age group. Tracheal or chest auscultation can be used to measure the provocative concentration of methacholine which induces audible wheeze (PCW) $[1,2]$. This technique does not require full co-operation of the children, and it has been demonstrated in older children that the value for PCW was similar to that causing a $20 \%$ fall in forced expiratory volume in one second (FEV1) [2]. Other authors have favoured measuring the transcutaneous oxygen tension $\left(\mathrm{tc} \mathrm{PO}_{2}\right)$, arguing that it is effort independent, reliable and repeatable and is superior to tracheal auscultation [3-5]. The methodology of the study by WILSON et al. [4] involved cessation of challenge when tc $\mathrm{PO}_{2}$ fell by $20 \%$, which may have censored the PCW data.

As part of a dose-ranging study of inhaled salmeterol in preschool children [6], the current study set out to reevaluate these two challenge endpoints. The aim of the study was to compare the sensitivity and safety of using audible wheeze and tc $\mathrm{PO}_{2}$ in a methacholine challenge in children $<4$ yrs of age.
University Dept of Paediatrics, Children's Hospital, Sheffield, UK

Correspondence: R.A. Primhak, University Division of Child Health, Children's Hospital, Western Bank, Sheffield S10 2TH UK. Fax: 441142755364

Keywords: Auscultation

child

methacholine

oximetry

Received: January 221998

Accepted after revision June 291999

This study was funded by GlaxoWellcome Research and Development, Greenford, UK.

Methods

Subjects

Children aged $<4$ yrs were recruited from the respiratory clinics in the Children's Hospital, Sheffield, UK. All children had a history of recurrent wheeze for at least 1 month documented by a physician on at least one occasion. Children with lower respiratory tract infection in the preceding 4 weeks or upper respiratory tract infection in the preceding week were excluded. The subjects refrained from using any bronchodilators for at least $8 \mathrm{~h}$ prior to testing. Inhaled steroids and cromoglycate were permitted for use throughout the study period. As part of the dose ranging study, each subject underwent two challenges with methacholine within a 3-7 day period, one of which was preceded by a dose of inhaled salmeterol. The study was approved by the South Sheffield Research Ethics Committee and informed consent was obtained from parents prior to the study.

Thirty-nine children (32 males) took part in the study completing 72 methacholine challenges in total. The mean \pm SD age of the children was $26.5 \pm 10.6$ months with a range of 8-46 months, and the median duration of symptoms was 18 (range 2-36) months. Thirty (77\%) of the children were receiving regular inhaled steroids, and two further children 
were receiving sodium cromoglycate. Twenty-three (59\%) of the children had a first degree relative with asthma. Ten children $(25.6 \%)$ had a history of eczema, and six (15\%) had a history of allergy to food or environmental allergens; the symptom pattern was variable, including children with atopic or viral episodic wheeze, and no attempt was made to delineate these phenotypes exactly. The authors were unable to obtain arterial oxygen saturation $\left(\mathrm{Sa}_{\mathrm{a}} \mathrm{O}_{2}\right)$ in eight tests (four children) and tc $\mathrm{PO}_{2}$ in 1 test, because of poor cooperation in each case.

\section{Challenge protocol}

The challenge was carried out using a continuous inhalation tidal breathing method as described by COCKCROFT et al. [7]. Following baseline tracheal and chest auscultation, isotonic saline was administered for 2 min from a Hudson nebulizer (Hudson, Temecula, CA, USA), connected to a compressed air cylinder delivering a flow rate of $8 \mathrm{~L} \cdot \mathrm{min}^{-1}$. Auscultation was repeated $5 \mathrm{~min}$ post saline nebulization. If no wheeze was heard, then a serial inhalation of doubling concentration of methacholine was started from a concentration of $0.03 \mathrm{mg} \cdot \mathrm{mL}^{-1}$ every $5 \mathrm{~min}$ to a maximum concentration of $8 \mathrm{mg} \cdot \mathrm{mL}^{-1}$. All tracheal and chest auscultation was perfor-med by the same observer within each challenge.

\section{Assessment of response}

The response to the challenge was monitored with a transcutaneous oxygen tension skin electrode (Kontron Medical, Basle, Switzerland), at $44^{\circ} \mathrm{C}$ placed on the anterior chest wall. The baseline value of $\operatorname{tc} \mathrm{PO}_{2}$ was obtained after a 1520 min equilibration period. $\mathrm{Sa}, \mathrm{O}_{2}$ was also monitored with a pulse oximeter (Nellcor N-200; Nellcor, Bicester, UK), throughout the study. Baseline values were obtained after a short period of stabilization. After each inhalation, tc $\mathrm{PO}_{2}$ values were recorded at $1 \mathrm{~min}$ intervals for $4 \mathrm{~min}$, as were $\mathrm{Sa}_{\mathrm{a}} \mathrm{O}_{2}$ values. Tracheal and chest auscultation were performed after 4 min.

The challenge was considered positive and terminated if audible wheeze was present over the trachea or chest, if the subject coughed persistently or if $\mathrm{Sa}_{\mathrm{a}} \mathrm{O}_{2}$ fell below $91 \%$. If crepitations or intercostal recessions were detected, the duration of the next concentration of methacholine was halved and the challenge proceeded until one of the end-point criteria was reached.

\section{Analysis}

A change which exceeded 3 SD of the mean population baseline-post saline difference in tc $\mathrm{PO}_{2}$ was considered to constitute a significant tc $\mathrm{PO}_{2}$ response, but results were also examined using the $15 \%$ fall described by WILSON et al. [4].

\section{Results}

The mean \pm SD baseline-post saline difference in tc $\mathrm{PO}_{2}$ was $0.14 \pm 0.97 \mathrm{kPa}$, giving a mean $+3 \mathrm{SD}$ of $3 \mathrm{kPa}$ as the limit of significance. All children reacted with wheeze or desaturation below $91 \%$ at or before the maximum concentration. Of the 72 tests, $56(78 \%)$ were terminated for wheeze, seven (10\%) for fall in $\mathrm{Sa}_{\mathrm{a}} \mathrm{O}_{2}$ and nine (12\%) showed simultaneous responses in both parameters. The pattern of response (wheeze or desaturation first) was concordant within the same child in $15 / 33$ evaluable pairs of tests.

\section{Outcome measures}

Wheeze. Wheeze occurred in 65/72 (90\%) tests at a methacholine concentrations of $\leq 8 \mathrm{mg} \cdot \mathrm{mL}^{-1}$. The distribution of provocative methacholine concentrations is shown in table 1 .

Arterial oxygen tension. Four children (eight tests) refused $\mathrm{Sa}, \mathrm{O}_{2}$ monitoring, leaving 64 evaluable tests. A saturation below $91 \%$ was seen in 16/64 (25\%) tests. In nine cases this was accompanied by a simultaneously observed wheeze, but in the other seven cases the test was terminated prior to wheeze occurring.

Transcutaneous oxygen pressure. One child refused tc $\mathrm{PO}_{2}$ monitoring, leaving 71 tests in which tc $\mathrm{PO}_{2}$ was available. If a $3 \mathrm{kPa}$ change in $\mathrm{tc} \mathrm{PO}_{2}$ was considered significant then a fall was observed in $27 / 71$ (38\%) of the tests; in only 10 of these tests did the fall occur at a lower methacholine concentration than wheeze or desaturation $<91 \%$. If a $15 \%$ change in tc $\mathrm{PO}_{2}$ was considered significant then $53 / 71$ $(75 \%)$ tests showed a fall; in 26 of the tests this occurred prior to wheeze or desaturation.

A significant rise was observed during the challenge in four of $71(6 \%)$ tests using the $3 \mathrm{kPa}$ cutoff, and in 20/71 (28\%) using the $15 \%$ cutoff. An example of such a test is shown in figure 1 . If all tests are considered positive when they cross the preset cut-off point for the first time (disregarding any subsequent rise in $t c \mathrm{PO}_{2}$ ), then the distribution of positive tests for both a $3 \mathrm{kPa}(3 \mathrm{SD})$ and a $15 \%$ fall in tc $P_{\mathrm{O}_{2}}$ are shown in figure 2 .

The challenges were generally tolerated well by the children. There was only one adverse event in the study. This child had moderately severe asthma. Both $\mathrm{Sa}, \mathrm{O}_{2}$ and tc $\mathrm{PO}_{2}$ dropped significantly and the child became cyanosed. However, the child responded promptly to nebulized $\beta_{2}$-agonist, as did all the other children at the end of the challenges. None of the children had unscheduled visits to their general practitioners or the hospital following either test.

Table 1. - Distribution of provocative methacholine concentrations inducing audible wheeze

\begin{tabular}{lc}
\hline Methacholine concentration $\mathrm{mg} \cdot \mathrm{mL}^{-1}$ & Number of tests \\
\hline 8 & 1 \\
4 & 4 \\
2 & 14 \\
1 & 18 \\
0.5 & 17 \\
0.25 & 8 \\
0.125 & 6 \\
0.06 & 2 \\
0.03 & 2 \\
Total & 72 \\
\hline
\end{tabular}




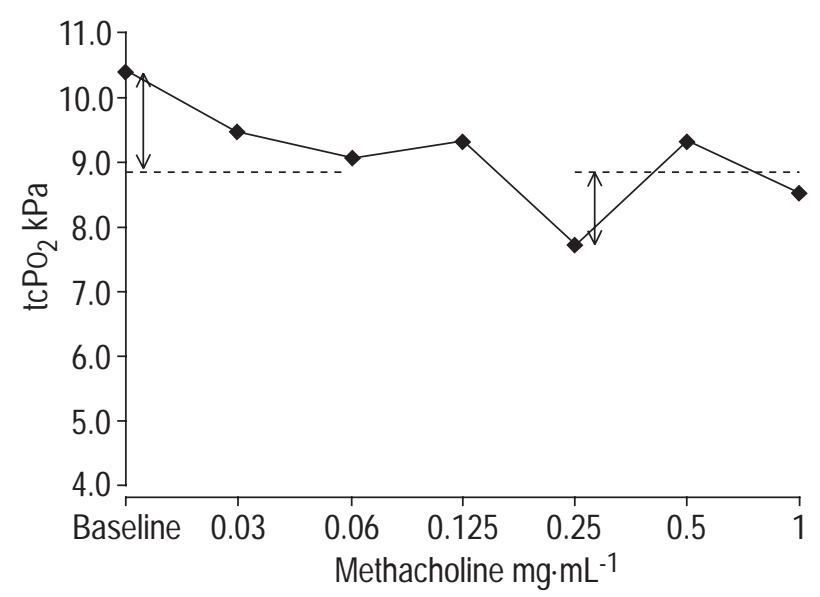

Fig. 1. - Example of a test containing a significant ( $>15 \%$; - - - and double headed arrow) rise in transcutaneous oxygen pressure $\left(\mathrm{tc} \mathrm{PO}_{2}\right)$ after an initial significant fall $(>15 \%$; - - - and double headed arrow).

\section{Discussion}

In this study it has been demonstrated that tracheal or chest auscultation can be used safely as an outcome measure in bronchial challenge tests in very young children when combined with pulse oximetry. In this study, a large proportion $(90 \%)$ of the methacholine challenges using the standard steady state method of bronchial provocation were terminated for tracheal wheeze. Auscultation of the trachea and chest were easily performed without causing any discomfort to the children. In a previous study by NoviSKI et al. [2] it was shown that the presence of tracheal wheeze correlated well with a $20 \%$ fall in FEV1. These authors have also used tracheal wheezing as part of a bronchial provocation test and have found it reliable and relatively easy to perform $[1,2]$. Others have used computerized breath sound analysis in similar research settings [8-10]. However, unlike tracheal or chest auscultation with the stethoscope, this digital analysis can be quite costly and requires highly experienced staff for interpretation. An editorial by GAVRIELY [11] pointed out some cautions and limitations when using breath sounds alone in provocation tests. These cautions highlighted the need for simultaneous monitoring of these children by other indirect tools such as a pulse oximeter or a tc $\mathrm{PO}_{2}$ monitor.

WILSON et al. [4] have previously compared tracheal wheeze and fall in tc $\mathrm{PO} 2$ as outcome measures for methacholine challenge. They defined a $15 \%$ fall in tc $\mathrm{PO}_{2}$ as a positive response, and terminated the test if the tc $\mathrm{PO}_{2}$ fell by $20 \%$ or if wheeze was heard. They found that only $16 \%$ of positive challenges demonstrated wheeze. It is possible that the use of a tc $\mathrm{PO}_{2}$ fall of $20 \%$ as an indication to terminate the test may have artificially biased the data to favour tc $\mathrm{PO}_{2}$ as an outcome measure. $\mathrm{Sa}, \mathrm{O}_{2}$ was used in the current study as a safety measure which allowed the authors to safely observe the natural history of tc $\mathrm{PO}_{2}$ changes during the challenge. It was found that $28 \%$ of the tests showed a $15 \%$ fall in tc $\mathrm{PO}_{2}$ followed by an equivalent rise at a higher concentration of methacholine. This suggests that some of the falls in tc $\mathrm{PO}_{2}$ observed during methacholine challenge are not true reflectors of dose-dependent bronchoconstriction. The authors are unable to explain this phenomenon. It could be argued that the wheeze endpoint has been censored in a similar way, and that perseverance beyond PCW concentrations might result in lessening of airway obstruction. However, it is not considered, by the authors, to be ethical to test this hypothesis in human infants.

The choice of the threshold level for tc $\mathrm{PO}_{2}$ is also open to debate. WiLson et al. [4] used a $15 \%$ fall, which was chosen to reflect equivalence with a forced oscillation measurement, although their finding that the latter technique was unreliable in this context might cast some doubt on the validity of this cutoff. The present authors have examined their data using this cutoff for the sake of comparison, but on physiological grounds they prefer to use an absolute fall of $3 \mathrm{kPa}$, which represents the mean $\pm 3 \mathrm{SD}$ change after saline nebulization. The $15 \%$ threshold resulted in a much higher positive test rate, but over one quarter of the tests had inconsistent results.

A small proportion of the challenges $(10 \%)$ in the current study were terminated because of a fall of $\mathrm{Sa}_{\mathrm{a}} \mathrm{O}_{2}$ below $91 \%$. This threshold was chosen on clinical grounds as being a well-validated threshold of severity in acute asthma [12]. However, this was an uncommon reason for termination despite the falls observed in tc $\mathrm{PO}_{2}$, which suggests that the concerns expressed about the safety of PCW may have been overstated. Nevertheless, the authors would regard it as mandatory to monitor saturation during an infant methacholine challenge to detect the small number of infants who have clinically important desaturation without detectable wheeze.

a) $\quad \mathrm{tcPO}_{2}(3 \mathrm{SD})$

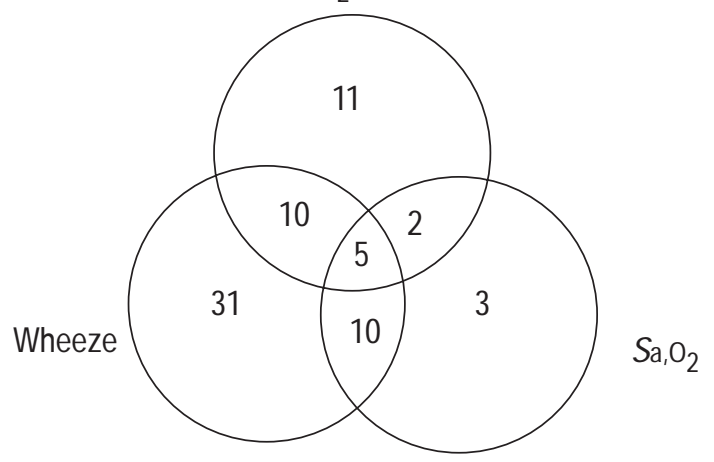

b)

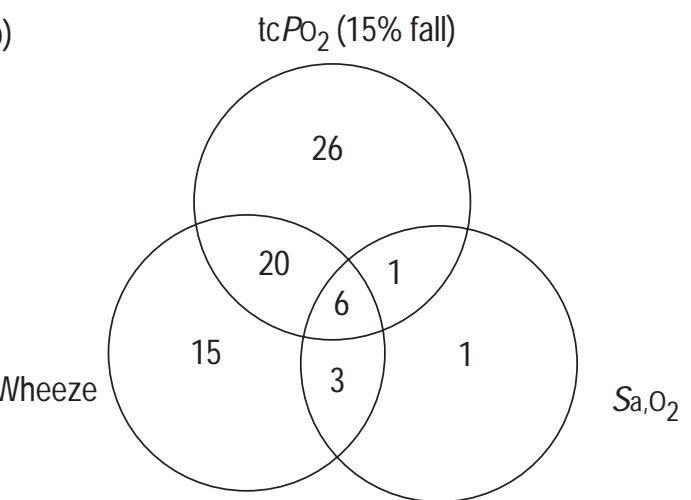

Fig. 2. - Venn diagrams showing which criterion was positive at the lowest methacholine concentration. The numbers of positive tests are shown using (a) $3 \mathrm{sD}$ fall in transcutaneous oxygen pressure $\left(\mathrm{tc} \mathrm{PO}_{2}\right)$ and (b) $15 \%$ fall in tc $\mathrm{PO}_{2}$ as end-points and including all "unevaluable" tests (see text). $\mathrm{Sa}_{2} \mathrm{O}_{2}$ : arterial oxygen saturation. 
In older children, studies of recorded lung sounds have shown good repeatability as a surrogate for spirometry in bronchial challenge tests [13]. It is possible that similar analysis of recorded lung sounds in young children will further improve the precision of PCW measurements.

In conclusion, it has been found that in infant methacholine challenge the transcutaneous oxygen monitor alone is not as robust a tool as was previously thought. It is suggested that a combination of tracheal/chest wheezing and pulse oximeter monitoring is a relatively safe and practicable outcome measure in bronchial provocation tests in infants and young children.

Acknowledgements. The authors would like to thank J. Allen for her invaluable help in performing the challenges.

\section{References}

1. Avital A, Bar Yishay E, Springer C, Godfrey S. Bronchial provocation tests in young children using tracheal auscultation. Pediatr 1988; 112: 591-594.

2. Noviski N, Cohen L, Springer C, Bar Yishay E, Avital A, Godfrey S. Bronchial provocation determined by breath sounds compared with lung function. Arch Dis Child 1991; 66: 952-955.

3. Wilson N, Phagoo S, Silverman M. Use of transcutaneous oxygen tension, arterial oxygen saturation, and respiratory resistance to assess the response to inhaled methacholine in asthmatic children and normal adults. Thorax 1991; 46: 433-437.

4. Wilson N, Bridge P, Phagoo S, Silverman M. The measurement of methacholine responsiveness in $5 \mathrm{yr}$ old children: three methods compared. Eur Respir J 1995; 8: 364-370.

5. Phagoo SB, Wilson NM, Silverman M. Repeatability of methacholine challenge in asthmatic children measured by change in transcutaneous oxygen tension. Thorax 1992; 47: 804-808.

6. Primhak R, Smith C, Yong S, et al. The bronchoprotective effect of inhaled salmeterol in pre-school children: a dose ranging study. Eur Respir $J$ 1999; 13: 78-81.

7. Cockcroft D, Killan D, Mellon J, Hargreave F. Bronchial reactivity to inhaled histamine: a method and a clinical survey. Clin Allergy 1977; 7: 235-243.

8. Spence D, Bentley S, Evans D, Morgan M. Effect of methacholine induced bronchoconstriction on the spectral characteristics of breath sounds in asthma. Thorax 1992; 47: 680-683.

9. Schreuer H, Diamant Z, Vanderschoot J, Zwinderman A, Dijkman J, Sterk P. Lung sounds during allergen-induced asthmatic responses in patients with asthma. Am J Respir Crit Care Med 1996; 153: 1474-1480.

10. Anderson K, Aitken S, Carter R, Macleod J, Moran F. Variation of breath sound and airway calibre induced by histamine challenge. Am Rev Respir Dis 1990; 141: 11471150 .

11. Gavriely N. Analysis of breath sounds in bronchial provocation tests. Am J Respir Crit Care Med 1996; 153 : 1469-1471.

12. Geelhoed G, Landau L, Le Souef P. Evaluation of $\mathrm{Sa}_{\mathrm{a}} \mathrm{O}_{2}$ as a predictor of outcome in 280 children presenting with acute asthma. Ann Emerg Med 1994; 23: 1236-1241.

13. Sprikkelman AB, Schouten JP, Lourens MS, Heymans HSA, van Aalderen WMC. Agreement between spirometry and tracheal auscultation in assessing bronchial responsiveness in asthmatic children. Respir Med 1999; 93: 102-107. 